\title{
The Geography of Poverty: Evidence from the Punjab
}

\author{
Ali Cheema*, Lyyla Khalid"* and Manasa Patnam
}

\begin{abstract}
The article is the first comprehensive attempt at estimating the variation in the incidence, intensity and severity of poverty in the Punjab at the level of sub-provincial regions and districts. This estimation has been made possible because of the availability of the Multiple Indicators Cluster Survey (2003-04), which has a sample that is representative at the district-level. Estimates suggest the existence of a high poverty enclave in the south and the west regions of the Punjab. The incidence and severity of poverty in a majority of districts in this enclave, with a few exceptions, is extremely high with one out of every two households being poor on average. The high levels of poverty in this enclave contrast with the relatively low poverty in the more urbanized north, where households are well integrated into the national and international labor market. The paper also argues that there is tremendous variation in the poverty experience of the districts in the centre. Poverty incidence in the more urbanized and industrialized northern districts of the centre contrasts sharply with the experience of Kasur, Okara and Pakpattan, where the incidence and severity of poverty is extremely high. Finally, we find that in nine districts rural households do much worse in terms of poverty incidence than their urban counterparts. The gap between urban and rural poverty incidence and severity is highest within the district of Labore suggesting that urbanization co-exists with a large poor population that inhabits the periurban areas of the district. An important aim of development policy and poverty targeting is to bridge these multi-faceted divides in the geography of poverty.
\end{abstract}

JEL Classification: D33, I32

Keywords: Poverty, Pakistan

\footnotetext{
* Acting Head of Economics, Lahore University of Management Sciences (LUMS).

${ }^{* *},{ }^{* * *}$ Teaching Fellows, Economics Department, Lahore University of Management Sciences (LUMS).
} 


\section{Introduction}

During the last few years there has been a lot of interest in the analysis and estimation of poverty in Pakistan (FBS 2001, World Bank 2002 and 2005, Anwar and Qureshi 2002, Cheema 2005, Anwar et. a1. 2005, Jamal 2002 and 2007). However, the literature has largely confined itself to estimating changes in the mean incidence and severity of poverty at the national and provincial levels during the last decade. Far less attention has been paid to the spatial pattern of poverty or the "geography of poverty". The emphasis on spatial poverty, to the extent that it is emphasized, confines itself to estimating the differences in poverty between the provinces and between rural and urban areas. The literature remains largely silent about the spatial pattern of poverty at the sub-provincial and the district levels. Gazdar (1999) and Malik (2005) are two notable exceptions in that they report poverty incidence estimates at the level of sub-provincial regions.

Estimating and analyzing the spatial pattern of poverty at the subprovincial level is important for number of reasons. The Constitutional assignment of expenditure functions assigns essential social sector, physical infrastructure and other important poverty reduction expenditures to the provinces. At the most basic level, the design of poverty reduction programs at the provincial level will require the creation of map that shows the distribution in the incidence and severity of poverty at the district and the regional levels. Without this map, targeting poverty will be extremely difficult. Furthermore, as result of the Provincial Local Government Ordinances (2001), critical poverty reduction expenditures related to primary and secondary education and basic health care have been devolved to district governments. The major share of finances used to meet these district expenditures comes from the province and are allocated to the district governments on the basis of the Provincial Finance Commission (PFC) award. These awards determine both the distribution of the proceeds of the Provincial Consolidated Fund between the Provincial Government and the local governments, as well as the formula for the distribution of the Provincial Allocable Amount between the districts. The PFCs will only be able to give weight to poverty-reduction in their formula to the extent that poverty estimates are available at the district level.

Estimating the variation in the geography of poverty at the subprovincial level is also important because there is a large body of literature that suggests that sub-provincial regions differ in their resource base; the history and pattern of migration; historical and current occupation patterns; availability of infrastructure; land ownership patterns; availability of human 
capital assets; the operation of markets; the degree of urbanization; and in the structure of electoral politics (Alavi 1976, Darling 1947, Malik 2005, Wilder 1999, Jamal 2003 and Gazdar 1999). It is, therefore, instructive to estimate whether differences in the incidence and severity of poverty exist across different sub-provincial regions and districts that reflect different socio-economic structures.

The lack of emphasis, in the literature, on the spatial pattern of poverty at the sub-provincial level has been due to the lack of availability of data-sets that are representative at the district-level and below. The present article analyzes the spatial pattern of poverty in the Punjab province by estimating poverty incidence and severity measures at the level of the districts and the sub-provincial regions. It is able to do this because of the availability of the Government of Punjab's Multiple Indicators Cluster Survey $(2003-04)^{1}$ that has a sample representative at the district-level. This is the first comprehensive estimation of the spatial variation in poverty measures at the district-level using a data-set that is representative at this level. Section 2 provides a classification of sub-provincial regions that is used to report the differences in the incidence and severity of poverty. Sector 3 describes the methodology used to measure poverty and development deficits at the level of the regions and the districts. Section 4 presents the evidence regarding the differences in the incidence and severity of poverty and development deficits across different regions and districts of the Punjab. Section 5 concludes and highlights areas of future research.

\section{Defining the Regions}

In order to make the analysis tractable we report our estimates at the level of the district and sub-provincial regions. We adopt the classification of regions suggested by Wilder (1999). He divides Punjab into northern, central, southern and western regions (Figure-1) based on: "geographical boundaries, official district and (old) division borders, regional economic differences, variations in irrigation, agriculture, and cropping patterns, differences in farm-size and land tenure patterns, and distinct historical, cultural, and linguistic influences in each region” (pg. 34).

We prefer Wilder's (1999) classification over Gazdar (1999) and Malik's (1991 and 2005) because it is more nuanced and comprehensive and takes into account a wider range of factors in classifying different regions. Malik's (2005) classification restricts itself to agronomic zones; however,

\footnotetext{
${ }^{1}$ We are grateful to the Punjab Planning and Development Board for making the data-set available to us.
} 
given that our emphasis is not restricted to an analysis of rural poverty this classification appears to be too restrictive. Gazdar's classification places much more weight on the use of administrative boundaries for the purposes of defining the sub-provincial regions and places less weight on the pattern of electoral politics, the history of canal irrigation, and the level of urbanization. For this purpose we use the broadest regional classification available, which is provided by Wilder (1999).

\section{Figure-1: Regions of Punjab}

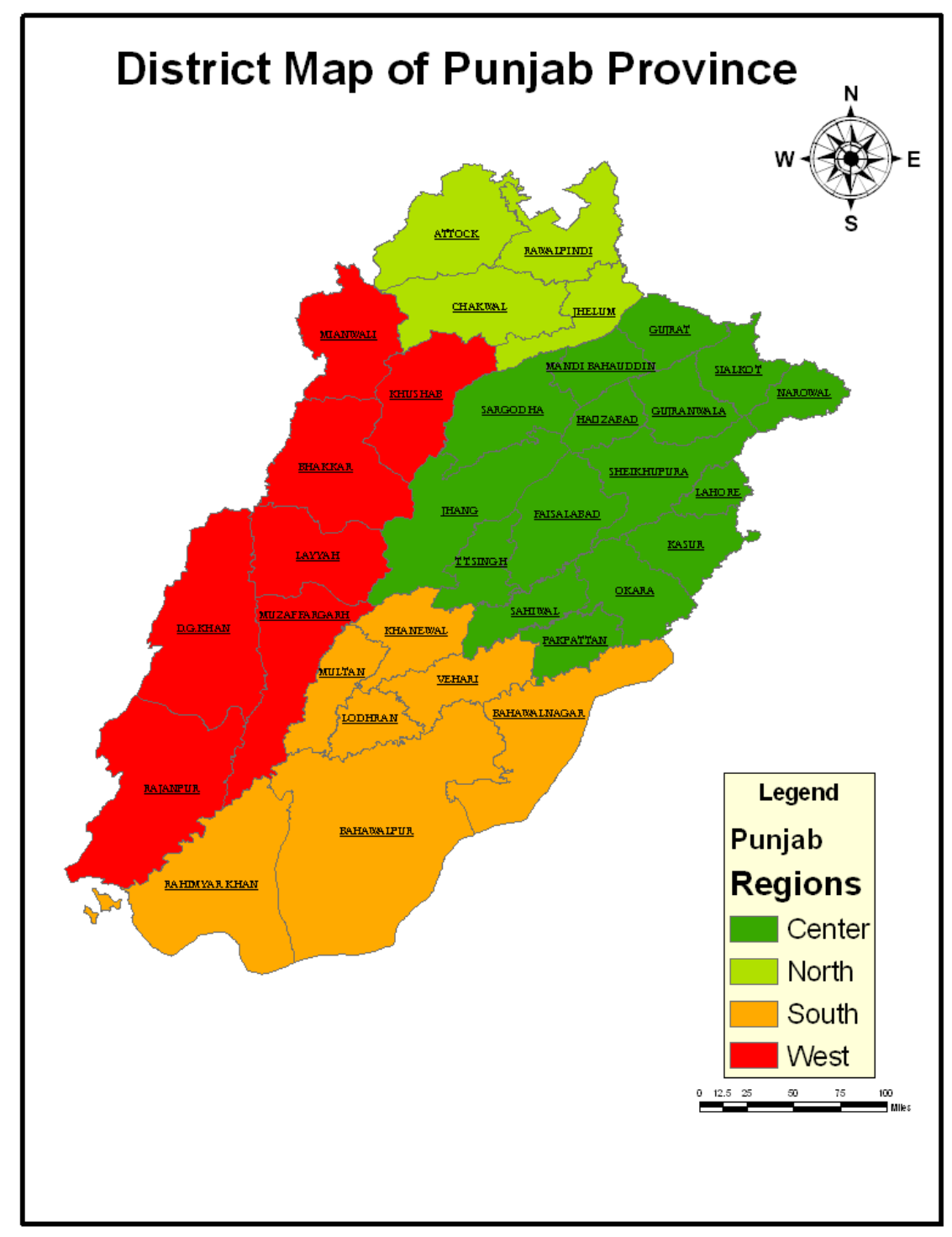


Table-1 and Table-2 describe important differences between the four regions of the Punjab. Table- 1 shows that income and expenditure per capita in the northern and central regions are higher than the Punjab mean. In contrast, income and expenditure per capita in the two remaining regions lie considerably below the provincial mean. Table- 2 shows that the northern and central regions are relatively more urbanized and have a much higher proportion of households that report living in concrete houses. The central region is clearly the most industrialized. Interestingly, there appears to be little difference in the percentage of rural households reporting lack of access to land across the four regions. Between the south and the west the former is much more urbanized and industrialized. This suggests that considerable differences exist in household income and wealth across the four regions. The northern and central regions have higher incomes and wealth followed by the south and then the west.

Table-1: Punjab Regions: Income and Expenditure Per Capita

\begin{tabular}{lccccc}
\hline & North & Centre & South & West & Punjab \\
\hline Mean Household P.C.E. & 1264 & 1181 & 901 & 886 & 1036 \\
& $(8.355)^{*}$ & $(14.15)^{*}$ & $(12.279)^{*}$ & $(12.348)^{*}$ & \\
Mean Household P.C.E. & 1080 & 1002 & 777 & 813 & 918 \\
(Rural) & $(7.584)^{*}$ & $(11.38)^{*}$ & $(11.183)^{*}$ & $(8.090)^{*}$ & \\
Mean Household P.C.I. & 1551 & 1580 & 1274 & 1090 & 1445 \\
& $(1.518)$ & $(6.338)^{*}$ & $(3.692)^{*}$ & $(6.104)^{*}$ & \\
Mean Household P.C.I. & 1204 & 1329 & 1121 & 1003 & 1215 \\
(Rural) & $(0.108)$ & $(3.732)^{*}$ & $(1.652)$ & $(3.050)^{*}$ & \\
\hline
\end{tabular}

Source: MICS (2003-04)

1. Absolute value of t-statistics in brackets (*indicates significance at 1\% level)

2. P.C.E refers to Per Capita Expenditure

3. P.C.I refers to Per Capita Income 
Table-2: Regional Socio-Economic Indicators

\begin{tabular}{|c|c|c|c|c|}
\hline & North & Centre & South & West \\
\hline $\begin{array}{l}\text { Urban Population (\% Population of the } \\
\text { Region) }\end{array}$ & 28.6 & 31.9 & 24.8 & 19 \\
\hline \% Registered Factories (2004) & 5 & 73 & 16 & 6 \\
\hline $\begin{array}{l}\text { \% Adults Reporting Daily Labor as Primary } \\
\text { Occupation }\end{array}$ & 35.8 & 42.9 & 60 & 52.1 \\
\hline \% Rural Households without Land & 51.7 & 60.4 & 59.1 & 52.2 \\
\hline \% Concrete Houses & 58.1 & 47.8 & 22.4 & 22.1 \\
\hline $\begin{array}{l}\text { Remittance as Proportion of Total Household } \\
\text { Income (\%) }\end{array}$ & 14.26 & 4.46 & 2.14 & 3.03 \\
\hline \% Households Reporting Migrant Labor & 22.9 & 8.7 & 5.8 & 7.6 \\
\hline $\begin{array}{l}\text { \% Working Age Population Employed in } \\
\text { Government }\end{array}$ & 27.3 & 10.5 & 6.7 & 8.4 \\
\hline
\end{tabular}

Source: MICS (2003-04); Punjab Development Statistics (2005); Population Census (1998)

Differences also exist in the employment pattern of households (Table-2). A greater proportion of households in the north rely on migrant labor and, as a result, households in this region report a higher share of remittances in their income as compared to the other three regions. Furthermore, this region has the greatest access to government and state employment. Households in the north appear to be much better integrated into the national and international labor market in comparison with the other regions. As opposed to this the south and the west have a much higher proportion of adults reporting daily labor as their primary employment.

Households in the southern and western regions do much worse in terms of educational and other public service delivery outcomes (Table-3). The only exception is sanitation and gas supply to rural areas, where the northern and central regions do as badly as the southern and western regions.

There are important differences in the economic and social histories of the four regions and in their historical endowments. The northern region has been the recruiting ground for state and military employment since the colonial period (Darling 1947, Yong 2005). Central Punjab districts have been the main beneficiaries of the colonial canal colonization projects (Ali 
1988), whereas agriculture in the north till date remains rain-fed. Central Punjab districts have also been the main beneficiaries of two population migrations; around the time of the colonial canal colonization projects and at the time of partition in 1947, which are argued to have positively impacted literacy and human capital outcomes in the affected districts (Bharadwaj et. a1. 2007, Ali 1988).

Table-3: Punjab: Educational and Public Service Delivery Indicators

\begin{tabular}{lrrrr}
\hline & North & Centre & South & West \\
\hline \% of 15-17 years (Boys): & & & & \\
Never Enrolled in School & 6.34 & 17.26 & 30.27 & 26.8 \\
Completed Primary & 14.90 & 23.90 & 24.73 & 22.17 \\
Completed Secondary & 43.07 & 32.61 & 26.77 & 29.20 \\
Completed Matric & 35.69 & 26.24 & 18.23 & 21.83 \\
\% of 15-18 Years (Girls): & & & & \\
Never Enrolled in School & 15.98 & 22.96 & 43.82 & 44.36 \\
Completed Primary & 22.73 & 22.99 & 21.72 & 22.75 \\
Completed Secondary & 27.13 & 28.03 & 18.70 & 17.69 \\
Completed Matric & 34.16 & 26.02 & 15.76 & 15.20 \\
HH with Access to: & & & & \\
Electricity & 93.6 & 92.3 & 72.6 & 70.9 \\
Electricity (Rural Areas) & 89.1 & 87.1 & 61.5 & 60.7 \\
Gas & 43.0 & 29.0 & 17.0 & 5.8 \\
Gas (Rural Areas) & 12.2 & 2.5 & 2.8 & 1 \\
Sanitation & 33.93 & 54.6 & 33.0 & 24.2 \\
Sanitation (Rural Areas) & 10.0 & 30.0 & 11.93 & 6.1 \\
\hline
\end{tabular}

Source: MICS (2003-04)

Given these differences in historical endowments - current income, human capital assets and wealth, and access to public services - it is important to estimate the differences in poverty across the four regions. It is also important to analyze the variation in district-level poverty within each region. We use measures of the incidence, intensity and severity of poverty 
as well as district-level deprivation rankings to analyze the spatial pattern of poverty and development at the level of the sub-provincial regions and the districts in the Province of the Punjab.

At the broadest level we would expect the north and centre to have much lower poverty because these are the high income regions of the province. These are also the regions where considerable proportion of adults have diversified out of daily labor as their primary occupation. We would expect the south to do marginally better than the west in terms of the incidence and severity of poverty because it is more urbanized and industrialized.

\section{Methodology}

\subsection{Poverty Figures}

Poverty is measured using the Foster, Greer and Thorbecke [FGT] (1984) class of measures. These measures not only allow us to estimate the incidence of poverty but also the intensity and severity of poverty. The FGT index can be defined as:

$$
P_{a}=\frac{1}{N} \sum_{i=1}^{n}\left[\frac{\left(Z-Y_{i}\right)}{Z}\right]^{a}
$$

where:

$$
\begin{aligned}
& \mathrm{N}=\text { Size of the population } \\
& \mathrm{N}=\text { Number of people below the poverty line } \\
& \mathrm{Z}=\text { Relevant poverty line } \\
& Y_{i}=\text { Income of the poor }
\end{aligned}
$$

The FGT index, $P_{a}$, is equivalent to the headcount ratio when a 0 and measures the incidence of poverty in given population of size $\mathrm{N}$. However, if 1, the FGT index is equivalent to the poverty gap index, which measures the depth of poverty or the average proportionate poverty gap in given population. Finally, if 2 , it is equivalent to the squared poverty gap index, which measures the severity of poverty or the average of the squared proportionate poverty gap.

The paper uses all three measures to estimate the difference in poverty across the districts and regions of Punjab. 


\subsection{Poverty Estimation}

Consistent with the literature for developing countries, we use a consumption based expenditure indicator rather than an income based indicator for the measurement of poverty. As argued by Deaton and Zaidi (2002) there are several reasons for doing so. Firstly, current consumption is less volatile to negative income shocks and hence is less variable over time. This is so especially in settings which are highly dependent on agriculture, where the households' stream of income fluctuates considerably over seasons and years. Secondly, there is a risk involved in measuring the income for households whose occupations are self-employment based. Often, these incomes (which are self-reported) are either underreported or reported with significant error. In such cases using income as measure for poverty will seriously bias our results.

Having chosen the consumption-based measure, we now discuss the methods used to calculate the poverty line and the real per capita expenditure of households, two essential measures that are needed in the calculation of poverty. The poverty line used in the paper is an inflationadjusted version of the national poverty line estimated by the Planning Commission (Cheema 2005) and validated by the World Bank $(2005)^{2}$. The national poverty line, which uses the calorific requirement approach and is based on calorie intake requirement of 2350 calories per adult equivalent per day, is estimated to be Rs. 723.4 per capita per month for 2000-01 (World Bank 2005). For the year 2003-04, the year of the MICS survey, adjusting for inflation using the Consumer Price Index (CPI), the poverty line stands at Rs. 807.53 per capita per month. Households with monthly consumption expenditure lower than this are classified as 'poor'.

In order to ensure comparability with the Planning Commission (Cheema 2005) and the World Bank (2005) estimates and analysis we use a single provincial poverty line for both rural and urban areas, which is based on the World Bank validated national poverty line. However, we check the robustness of our estimation using separate poverty lines for urban and rural areas that are inflation-adjusted versions of the urban and rural national poverty lines reported in World Bank (2002). Robustness is also checked by employing different methods to deflate the consumption expenditure of households.

\footnotetext{
${ }^{2}$ For details see (http://siteresources.worldbank.org/INTSAREGTOPPOVRED/13375671152551765388/20987772/ PovertyHCR2000-2005.pdf)
} 
In order to construct a consumption aggregate, we include the following consumption items: food items, non-food items, house rent and current expenditure on maintenance of house. We exclude specifically expenditure on durable goods (clothing, purchase of assets etc.), payments of taxes and loan repayments. Hedonic housing regressions were used to impute the value of housing consumption wherever information on rents was missing i.e. if the household owns the house and does not pay rent. Following PRSP (2003), we regress house rent of rented households on a number of house characteristics such as number of rooms, facilities provided in the house (gas, electricity, water, telephone) etc, and then using the parameters developed by our model impute rent for the rest of the population. Aggregating over the above mentioned items gives us an estimate of the total monthly expenditure for each household.

This total monthly expenditure is however only a nominal measure. In countries where spatial price differences are very large, these differences have to be taken into account in our expenditure calculations. For this, we make use of the Paasche price index to deflate the nominal value of total monthly expenditures in order to control for spatial price differences. This procedure is akin to calculating a money metric measure of utility for each household (Deaton and Zaidi, 2002). We calculate our index based on only food items. These price indices implicitly assume that costs of living are exactly proportional to the relative food prices faced by the household. Further, since household level unit values tend to be quite noisy and contain many outliers, we calculate our index as cluster or region based where clusters are the Primary Sampling Unit defined as per the MICS survey methodology. Given this, the real value of total monthly expenditure of household $h$ is:

$$
x_{r}^{h}=\frac{x_{n}^{h}}{P^{c}}
$$

and the Paasche price index, $P^{c}$ is given by:

$$
P^{c}=\left\{\sum w_{k}^{c}\left(\frac{p_{k}^{o}}{p_{k}^{c}}\right)\right\}^{-1}
$$

where $w_{k}^{c}$ is the share of cluster $c^{\prime} s$ budget devoted to food item $k$; $p_{k}^{o}$ is the Punjab level median price for food item $k$, and $p_{k}^{c}$ is the cluster level median price for food item $k$. These cluster level price indices are then normalized by the average price indices. 
Finally, to arrive at the per-capita value for total expenditure we adjust the real total monthly expenditure by the size and demographics of the household. As various members of household have 'differing needs' based on their age, sex, and other such demographic characteristics we must account for the costs of children and old people relative to adults. We use the method of equivalence scale, where each household member is given a weight according to their sex and age, to arrive at a per capita measure for expenditure. Here, we rely on the equivalence scales (see Table-4) used in the PRSP (2003).

Table-4: Equivalence Scales

\begin{tabular}{lcc}
\hline Age Bracket & Energy Per Person & Daily Requirement \\
\hline Children & & \\
$<1$ & 1010 & 0.4298 \\
$1-4$ & 1304 & 0.5549 \\
$5-9$ & 1768 & 0.7523 \\
Males & & \\
$10-14$ & 2,816 & 1.1983 \\
$15-19$ & 3,087 & 1.3136 \\
$20-39$ & 2,760 & 1.1745 \\
$40-49$ & 2,640 & 1.1234 \\
$50-59$ & 2,640 & 1.0468 \\
60 or more & 2,146 & 0.1932 \\
Females & & \\
$10-14$ & 2464 & 1.0485 \\
$15-19$ & 2332 & 0.9881 \\
$20-39$ & 2080 & 0.8851 \\
$40-49$ & 1976 & 0.8409 \\
$50-59$ & 1872 & 0.7966 \\
60 or more & 1632 & 0.6945 \\
\hline
\end{tabular}

Source: PRSP (2003) 


\subsection{Deprivation Indices}

The paper also analyzes the extent to which there is an overlap between district-level poverty and district-level socio-economic deprivation. Socio-economic deprivation may be assessed through a variety of economic and social measures. Following the work of Jamal et al (2003) we compute indices of multiple socioeconomic deprivations, which are based on separate indicators of development deprivation.

District rankings on the basis of deprivation indices are extremely sensitive, not only to the composition of the indices under consideration but also to the methodology employed. In the analysis below we compute four separate deprivation indices for the districts of the Punjab using principal component analysis (PCA). PCA transforms a number of correlated variables into a smaller number of uncorrelated variables using the eigenvector values obtained.

Deprivation indices are calculated using a combination of the following six indicators:

1) Education: Male illiteracy rate (10 years and above); female illiteracy rate (10 years and above); male proportion out of school children; and female proportion out of school children.

2) Housing Quality: Proportion of adobe houses; persons per room; percentage of housing units with one room; percentage of nonowner households; and households with no latrine facility.

3) Housing Services: Percentage of un-electrified households; percentage of households without gas; percentage of households with no inside piped water connection; and households with no telephone connection.

4) Employment: Unemployment rate [15-65 years].

5) Poverty: Head Count Ratios

6) Social Indicators: Under 5 mortality rates; ante-natal care by skilled health workers.

Using these indicators the following indices are computed:

Index 1 Consists of items to 5 (i.e. Education, Housing Quality, Housing Services, Employment, Poverty HCR's). 
Index 2 Consists of items to 6 (i.e. Education, Housing Quality, Housing Services, Employment, Poverty HCR's, Social Indicators).

Indices $3 \& 4$ are created by omitting the Head count ratios (5) from indices 1 and 2 respectively.

\section{The Geography of Poverty}

\subsection{Sub-Provincial Regions}

Table-5 and Table- 6 report the three poverty measures for all four sub-regions and for their individual districts and for the rural areas of the sub-regions and the districts, respectively. In addition, these tables report mean household per capita expenditure and the mean expenditure of poor households.

Table-5: Region Wise Poverty - All Regions

\begin{tabular}{clrrrrrr}
\hline \multirow{2}{*}{ Region District } & \multicolumn{6}{c}{ All Areas: Urban and Rural } \\
\cline { 3 - 7 } & & \# HH & hcr & pg & pg sq & pce & pce poor \\
\hline 1 & Rawalpindi & 1,330 & 0.207 & 0.043 & 0.013 & 1547.042 & 639.575 \\
1 & Attock & 607 & 0.301 & 0.066 & 0.022 & 1568.043 & 629.196 \\
1 & Chakwal & 611 & 0.281 & 0.062 & 0.019 & 1252.47 & 628.702 \\
1 & Jhelum & 559 & 0.198 & 0.041 & 0.012 & 1393.647 & 639.438 \\
\hline North & & 3,107 & 0.238 & 0.051 & 0.016 & 1465.618 & 634.474 \\
\hline 2 & Faisalabad & 1976 & 0.380 & 0.083 & 0.027 & 1143.882 & 629.965 \\
2 & Jhang & 1,051 & 0.402 & 0.072 & 0.024 & 1140.855 & 621.586 \\
2 & T.T. Singh & 738 & 0.319 & 0.072 & 0.024 & 1220.343 & 624.722 \\
2 & Gujranwala & 1,238 & 0.323 & 0.076 & 0.026 & 1275.822 & 616.180 \\
2 & Gujrat & 700 & 0.251 & 0.051 & 0.015 & 1379.607 & 641.412 \\
2 & Hafizabad & 547 & 0.361 & 0.089 & 0.030 & 1281.878 & 607.385 \\
2 & Mandi & 608 & 0.180 & 0.032 & 0.009 & 1560.776 & 661.821 \\
& Bahauddin & & & & & & \\
2 & Narowal & 603 & 0.330 & 0.065 & 0.018 & 1213.315 & 647.403 \\
2 & Sialkot & 883 & 0.225 & 0.049 & 0.017 & 1475.347 & 630.354 \\
2 & Kasur & 843 & 0.494 & 0.128 & 0.045 & 1032.164 & 597.421 \\
2 & Okara & 747 & 0.508 & 0.145 & 0.056 & 986.310 & 577.102 \\
2 & Sheikhupura & 1,092 & 0.317 & 0.070 & 0.023 & 1169.217 & 627.337 \\
2 & Pakpattan & 607 & 0.535 & 0.155 & 0.058 & 971.268 & 573.511 \\
2 & Sahiwal & 748 & 0.438 & 0.120 & 0.045 & 1160.725 & 585.720 \\
2 & Sargodha & 1,146 & 0.387 & 0.098 & 0.036 & 1302.406 & 603.121 \\
2 & Lahore & 3,253 & 0.229 & 0.050 & 0.015 & 1716.464 & 631.409 \\
\hline
\end{tabular}




\begin{tabular}{clrrrrrr}
\hline Center & & 16,780 & 0.338 & 0.080 & 0.027 & 1311.521 & 615.178 \\
\hline 3 & Bahawalnagar & 828 & 0.448 & 0.141 & 0.062 & 1613.792 & 553.363 \\
3 & Bahawalpur & 1,046 & 0.523 & 0.182 & 0.086 & 1058.253 & 525.549 \\
3 & Rahimyar Khan & 971 & 0.550 & 0.161 & 0.069 & 1081.406 & 571.341 \\
3 & Multan & 1,254 & 0.473 & 0.122 & 0.042 & 1175.460 & 598.011 \\
3 & Khanewal & 804 & 0.457 & 0.103 & 0.033 & 1120.867 & 624.362 \\
3 & Lodhran & 554 & 0.593 & 0.161 & 0.060 & 954.941 & 587.813 \\
3 & Vehari & 798 & 0.309 & 0.074 & 0.025 & 1323.463 & 612.228 \\
\hline South & & 6,255 & 0.478 & 0.136 & 0.055 & 1191.617 & 577.728 \\
\hline 4 & D.G. Khan & 707 & 0.507 & 0.154 & 0.063 & 1014.103 & 561.779 \\
4 & Layyah & 536 & 0.477 & 0.126 & 0.044 & 972.588 & 592.814 \\
4 & Muzaffargarh & 801 & 0.558 & 0.167 & 0.066 & 1195.997 & 564.997 \\
4 & Rajanpur & 611 & 0.671 & 0.216 & 0.086 & 782.6453 & 546.787 \\
4 & Bhakkar & 559 & 0.493 & 0.126 & 0.043 & 1041.948 & 600.757 \\
4 & Khushab & 560 & 0.387 & 0.099 & 0.035 & 1419.402 & 600.762 \\
4 & Mianwali & 539 & 0.410 & 0.100 & 0.036 & 1231.816 & 609.563 \\
\hline West & & 4,313 & 0.506 & 0.144 & 0.055 & 1093.376 & 576.882 \\
\hline
\end{tabular}

Source: MICS (2003-04)

1. $h c r$ is the FGT measure of Head Count Ratio

2. $p g$ is the FGT measure of Poverty Gap; $p g s q$ is the FGT measure of Average Normalized Poverty Gap Squared

3. $p c e$ is the Mean Per Capita Expenditure; pce poor is the Mean Per Capita Expenditure within the estimated poor

Table-6: Region Wise Poverty-Rural

\begin{tabular}{clrccccc}
\hline \multirow{2}{*}{ Region District } & \multicolumn{6}{c}{ All Areas: Urban and Rural } \\
\cline { 3 - 8 } & & \# HH & hcr & pg & pg sq & pce & pce poor \\
\hline 1 & Rawalpindi & 518 & 0.231 & 0.048 & 0.015 & 1367.854 & 640.053 \\
1 & Attock & 432 & 0.321 & 0.067 & 0.021 & 1642.566 & 637.330 \\
1 & Chakwal & 432 & 0.321 & 0.074 & 0.024 & 1079.466 & 628.702 \\
1 & Jhelum & 380 & 0.200 & 0.042 & 0.012 & 1298.282 & 637.368 \\
\hline North & & 1,762 & 0.269 & 0.058 & 0.018 & 1349.497 & 632.789 \\
\hline 2 & Faisalabad & 949 & 0.414 & 0.089 & 0.028 & 1038.042 & 633.271 \\
2 & Jhang & 767 & 0.406 & 0.091 & 0.030 & 1096.056 & 625.051 \\
2 & T.T. Singh & 526 & 0.330 & 0.077 & 0.026 & 1176.920 & 618.463 \\
2 & Gujranwala & 514 & 0.416 & 0.106 & 0.038 & 1151.264 & 600.410 \\
2 & Gujrat & 526 & 0.249 & 0.050 & 0.014 & 1378.737 & 644.863 \\
\hline
\end{tabular}




\begin{tabular}{clrrrrrr}
\hline 2 & Hafizabad & 380 & 0.360 & 0.085 & 0.028 & 1249.185 & 615.067 \\
2 & Mandi & 430 & 0.220 & 0.039 & 0.010 & 1491.834 & 664.697 \\
& Bahauddin & & & & & & \\
2 & Narowal & 424 & 0.382 & 0.077 & 0.022 & 1115.615 & 643.021 \\
2 & Sialkot & 434 & 0.296 & 0.071 & 0.027 & 1239.740 & 611.666 \\
2 & Kasur & 557 & 0.515 & 0.137 & 0.049 & 1053.562 & 591.514 \\
2 & Okara & 568 & 0.517 & 0.149 & 0.058 & 972.2479 & 574.985 \\
2 & Sheikhupura & 807 & 0.286 & 0.058 & 0.017 & 1195.906 & 641.517 \\
2 & Pakpattan & 429 & 0.561 & 0.164 & 0.062 & 892.6119 & 570.913 \\
2 & Sahiwal & 570 & 0.464 & 0.126 & 0.047 & 1044.120 & 588.050 \\
2 & Sargodha & 659 & 0.453 & 0.117 & 0.044 & 1217.961 & 598.667 \\
2 & Lahore & 789 & 0.472 & 0.115 & 0.038 & 1035.076 & 610.911 \\
\hline Center & & 9,327 & 0.400 & 0.097 & 0.034 & 1135.213 & 610.717 \\
\hline 3 & Bahawalnagar & 618 & 0.493 & 0.159 & 0.072 & 1592.693 & 545.806 \\
3 & Bahawalpur & 605 & 0.634 & 0.224 & 0.106 & 862.7054 & 522.388 \\
3 & Rahimyar Khan & 757 & 0.597 & 0.184 & 0.082 & 974.8011 & 557.592 \\
3 & Multan & 621 & 0.584 & 0.158 & 0.056 & 909.760 & 589.165 \\
3 & Khanewal & 624 & 0.443 & 0.097 & 0.030 & 1116.713 & 629.463 \\
3 & Lodhran & 379 & 0.630 & 0.182 & 0.069 & 927.3738 & 573.639 \\
3 & Vehari & 619 & 0.326 & 0.078 & 0.027 & 1278.434 & 612.893 \\
\hline South & & 4,223 & 0.526 & 0.154 & 0.063 & 1100.819 & 570.761 \\
\hline 4 & D.G. Khan & 527 & 0.593 & 0.188 & 0.078 & 892.444 & 550.806 \\
4 & Layyah & 382 & 0.510 & 0.142 & 0.050 & 871.265 & 582.722 \\
4 & Muzaffargarh & 622 & 0.625 & 0.194 & 0.079 & 1079.043 & 556.304 \\
4 & Rajanpur & 431 & 0.705 & 0.233 & 0.094 & 726.027 & 539.668 \\
4 & Bhakkar & 380 & 0.578 & 0.157 & 0.056 & 954.563 & 588.458 \\
4 & Khushab & 379 & 0.403 & 0.103 & 0.036 & 1380.194 & 600.466 \\
4 & Mianwali & 362 & 0.425 & 0.111 & 0.041 & 1300.744 & 596.573 \\
\hline West & & 3,083 & 0.560 & 0.166 & 0.065 & 1019.761 & 566.955 \\
\hline & & & & & & &
\end{tabular}

Source: MICS (2003-04)

1. hor is the FGT measure of Head Count Ratio

2. $p g$ is the FGT measure of Poverty Gap; pg sq is the FGT measure of Average Normalized Poverty Gap Squared

3. pce is the Mean Per Capita Expenditure; pce poor is the Mean Per Capita Expenditure within the estimated poor

The tables show the existence of a poverty ladder between the four sub-regions. The north is at the bottom of the ladder followed by the centre and the south and west are considerably high up on this ladder. Whether 
we look at overall poverty measures (Table-5) or rural poverty measures (Table-6) the south and the west constitute the high poverty enclave of the Punjab.

In terms of overall poverty incidence the gap in the headcount ratios between the north and centre are far less than the gap between the centre and the south and the centre and the west. The same pattern is true for the incidence of rural poverty. The south and west have similar and high poverty headcount ratios of around $50 \%$ and the incidence of poverty in these regions is much higher than the incidence of poverty in the north and the centre. That is, one out of two households in these regions is likely to be poor.

There appears to be a strong correlation between the differences in the incidence of poverty across the four regions and the differences in the intensity and severity of poverty. The intensity and severity of poverty is much higher in the south and west, which are the very regions where the incidence of poverty is the highest. It is in these regions that the mean expenditure per capita of poor households is the lowest. Estimations suggest that the severity of overall and rural poverty in the south and west are twice that found in central Punjab.

Analysis of these tables also shows that there is a prima facie association between poverty measures and mean household expenditure per capita across the four regions. Again this is true for overall and rural poverty measures. However, closer analysis of the tables suggests that the association is not very strong because the ratio of mean expenditure per capita for the centre and the south and the centre and the west is not as large as the gap in poverty measures for these regional pairs. This suggests that the difference in mean income, while important, is perhaps a less essential factor than the distribution of income and expenditure within each region and the potential for income mobility within them. There is certainly a need to identify the causal determinants of poverty across the different regions, which is an important area of future research.

\subsection{Robustness}

Table-7 estimates poverty incidence at the regional level using different methods. Column (1) uses a spatially deflated expenditure per capita measure and measures poverty incidence using the poverty line of Rs. 807.53. Column (2) reports an undeflated estimate, while column (3) reports poverty incidence using separate inflation adjusted urban and rural poverty lines defined in World Bank (2002). 
Table-7: Sensitivity Estimates

\begin{tabular}{lccc}
\hline & $(1)$ & $(2)$ & $(3)$ \\
\hline North & 23.60 & 19.78 & 28.31 \\
Center & 33.48 & 34.09 & 38.34 \\
South & 47.42 & 53.07 & 51.52 \\
West & 50.32 & 56.79 & 54.10 \\
\hline Punjab & 37.71 & 39.73 & $\mathbf{4 2 . 2 5}$ \\
\hline
\end{tabular}

Source: MICS (2003-04)

Column (1) estimates poverty using spatially deflated expenditure per-capita measure on the basis of Rs.807.53 as a poverty line.

Column (2) estimates poverty using total expenditure per-capita measure on the basis of Rs.807.53 as a poverty line.

Column (3) estimates poverty using total expenditure per-capita measure on the basis of separate poverty lines for urban and rural regions: Rs. 820.1 for rural areas and Rs. 926 for urban areas.

The interesting things to note are as follows. Regional poverty headcount ratios are sensitive to the method of estimation employed. Depending on the method of estimation employed, the regional headcount estimates could be over or understated by up to $6 \%$. Therefore, it is imperative that a consistent methodology is adopted by economists working on poverty estimations in Pakistan. Having said this, it is also important to note that the poverty incidence rank of different regions is not sensitive to the method of estimation employed. No matter what method of estimation is chosen, the north and centre do significantly better in terms of poverty incidence than the south and west and the differences between them do not change very much.

\subsection{Districts}

Table-5, Table-6, Figure-2, Figure-3, Figure-4 and Figure-5 provide interesting insights into the pattern of district-level poverty in the Punjab. These tables and figures show that in each region, there is considerable variation in the incidence and severity of poverty across the different districts. 
Figure-2: Poverty Head Count Ratio (FGT Measure)

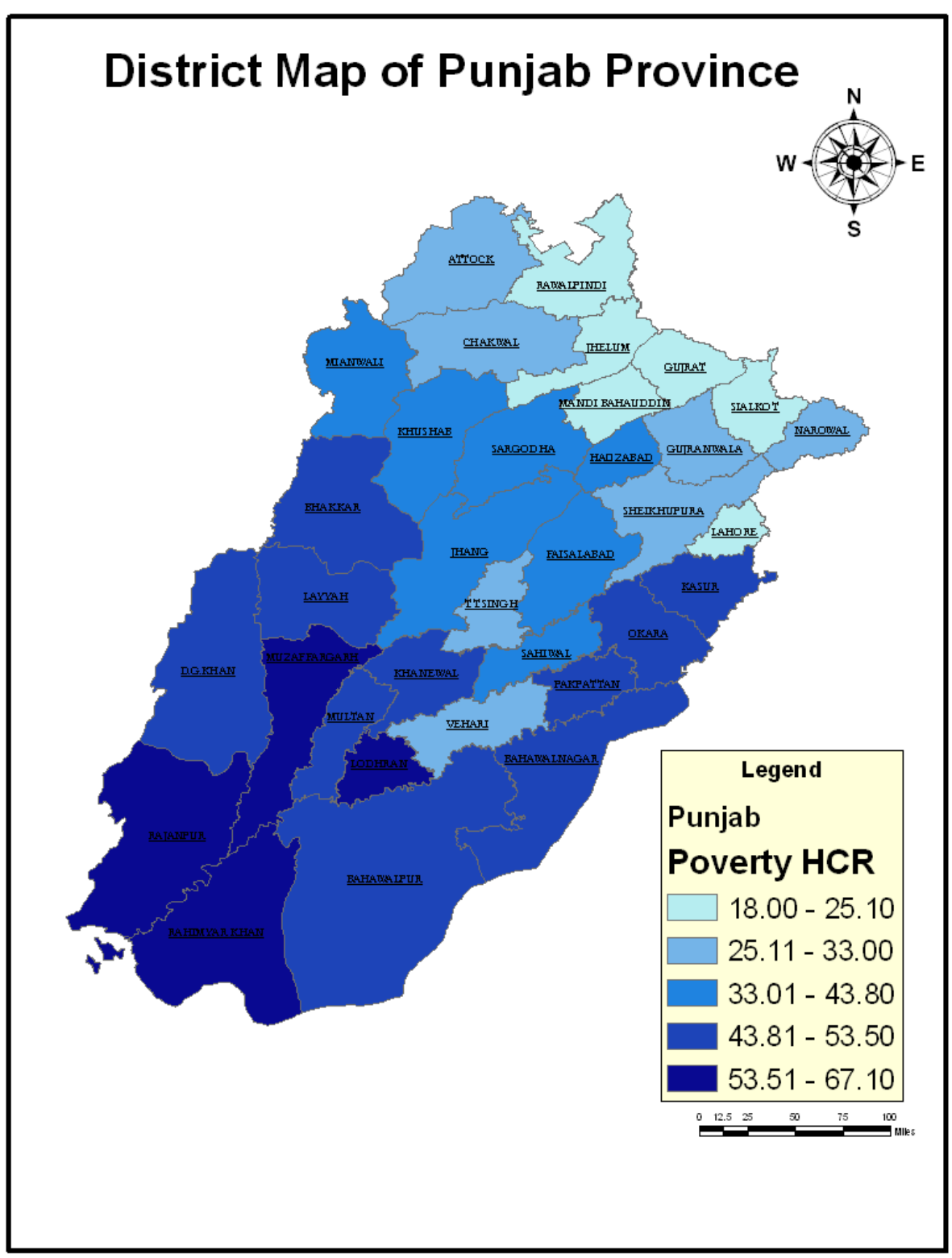


Figure-3: Poverty Head Count Ratio (FGT Measure): Rural Areas

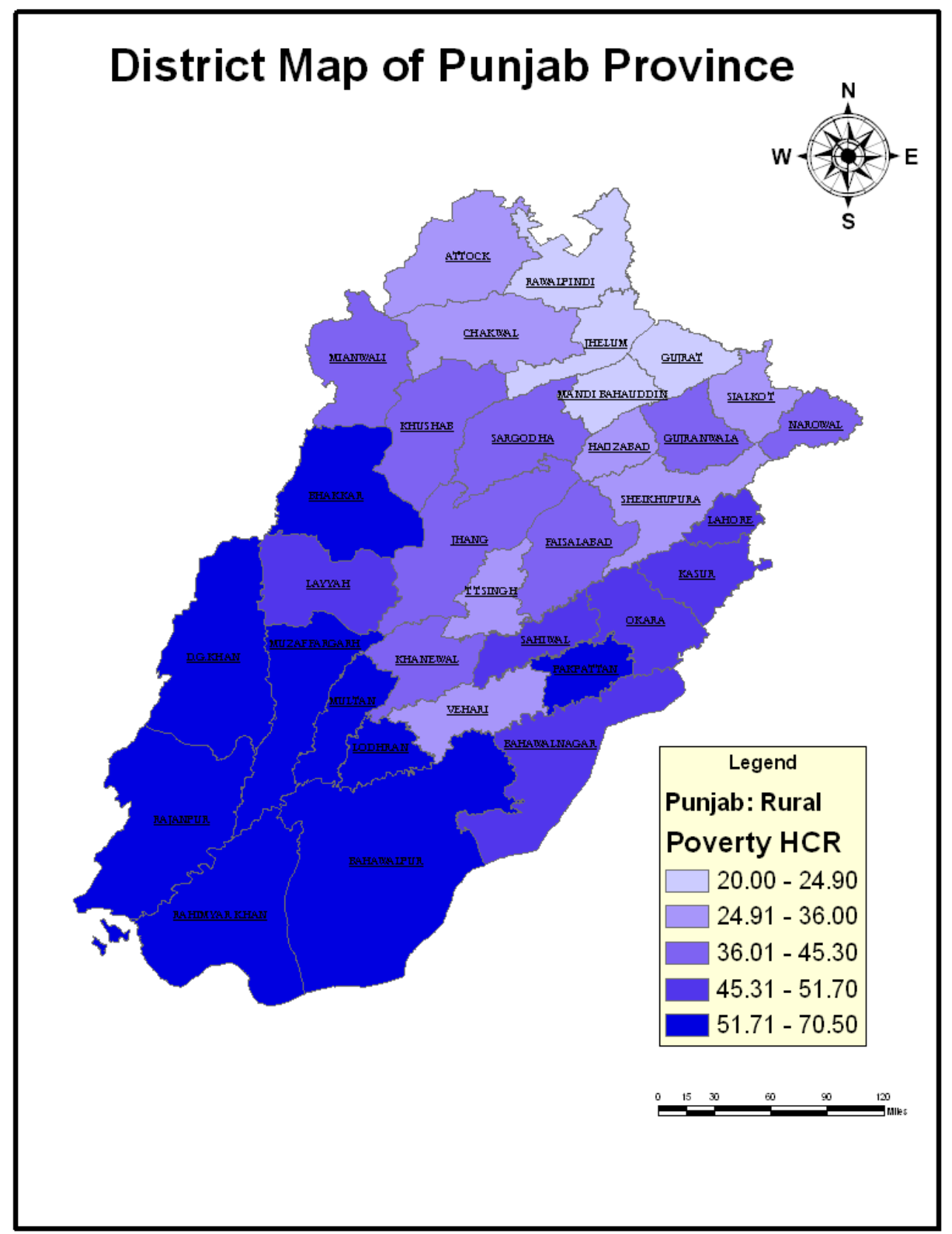


Figure-4: Poverty Gap Squared (FGT Measure)

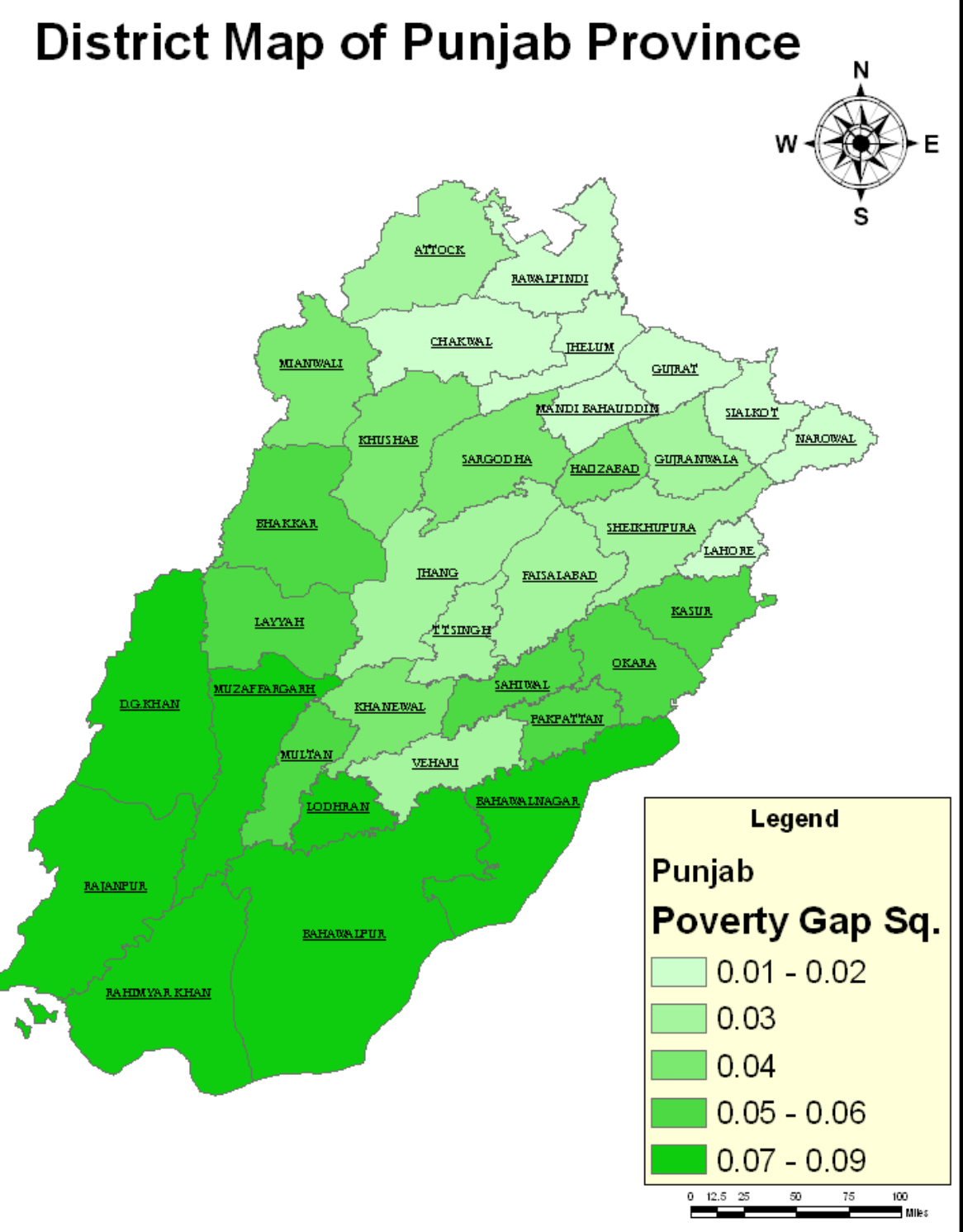


Figure-5: Poverty Gap Squared (FGT Measure): Rural Areas

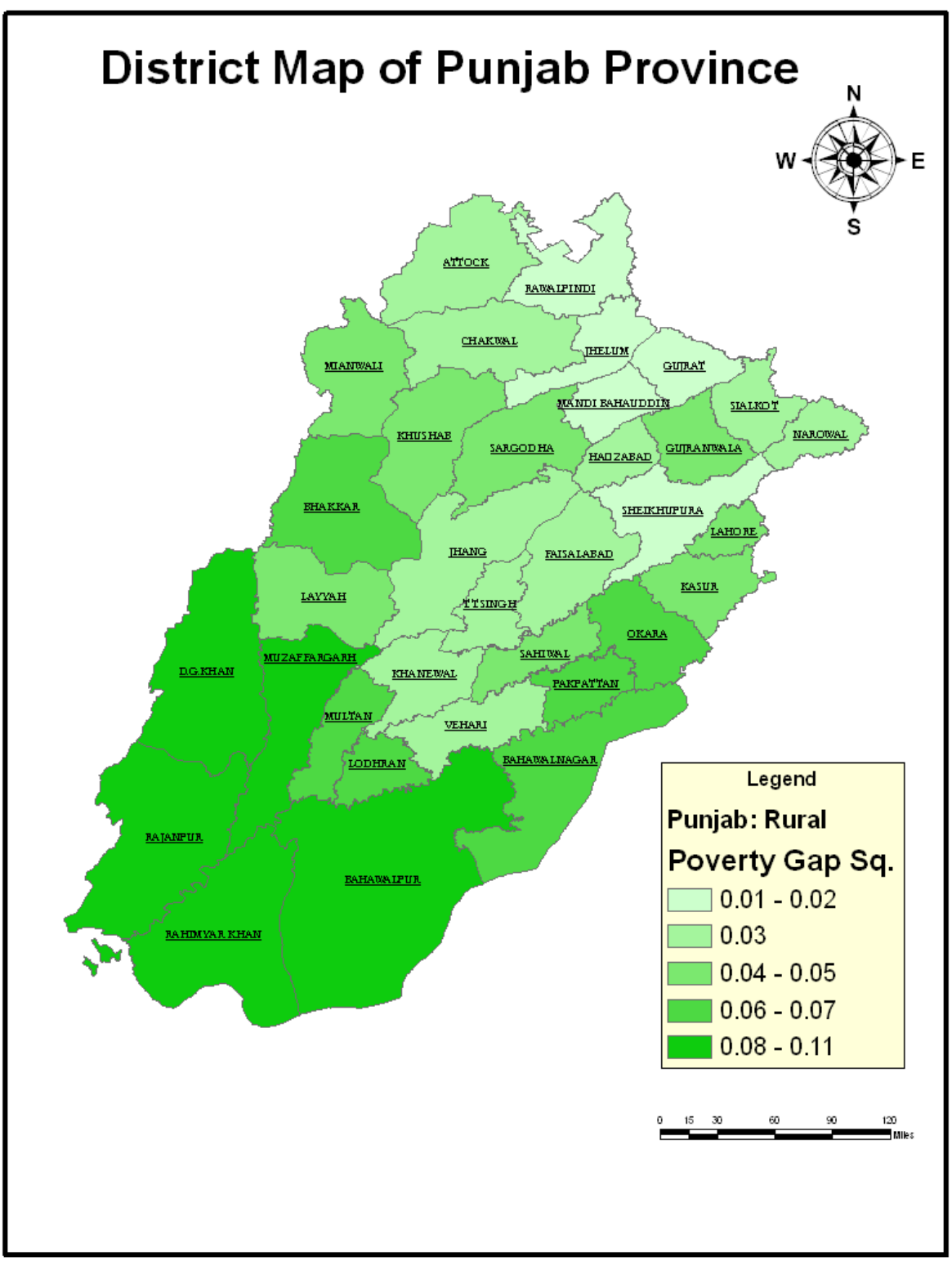

In the north, Attock and Chakwal do much worse in terms of the incidence and severity of overall and rural poverty than the other two districts of the region. However, in spite of doing much worse than the other two districts of the north, they do much better compared to the mean poverty incidence and the severity of poverty in the other regions (Tables-5 \& 6) and Figures 2-5. Interestingly, the severity of overall and 
rural poverty in all the districts of the north is much lower than the severity found in the other districts of the province (Figure 4-5).

Central Punjabi districts have a tremendous variation in terms of the incidence and severity of poverty (Figures 2-5). In terms of overall poverty incidence and severity the northern and/or more urbanized and industrialized districts of Lahore, Sialkot, Mandi Bahauddin and Gujrat appear to be similar to the districts of north Punjab. These districts, with the exception of Lahore, perform similar to northern districts in terms of rural poverty incidence as well. At the other extreme, Kasur, Okara and Pakpattan have overall and rural poverty headcount ratios that are higher than the southern Punjab mean indicating the existence of a high poverty enclave within central Punjab. It appears that there is tremendous variation in the range of poverty experiences in central Punjabi districts and the causes of this variation need to be understood if policy is to make headway in terms of poverty reduction.

There is much more homogeneity in terms of poverty experiences in the south and west. Most districts have overall poverty headcount ratios that range around $50 \%$ and rural poverty incidence is higher than the incidence of overall poverty in most districts (Figures 2-3). Extreme incidence of overall poverty, more than $60 \%$, is found in Rajanur and in terms of rural poverty it is found in Rajanpur, Muzzaffargarh, D.G. Khan, Lodhran, Rahimyar Khan and Bahawalpur.

In spite of this homogeneity there are clear outliers where poverty is similar to the central Punjab mean (Figures 2-5). The starkest outlier is Vehari in terms of both the incidence and severity of overall and rural poverty. Its incidence and severity are less than the central Punjab mean. In terms of the severity of poverty and the incidence of rural poverty, Khanewal's experience is in line with the central Punjab mean. Finally, in the west Khushab and Mianwali have poverty headcount ratios and severity measures that are in line with the central Punjab mean. Again, future research must try and explain why these districts have different poverty reduction paths from their neighbors.

An important finding is that in nine districts of the Punjab, rural households do much worse in terms of the incidence of poverty in comparison to urban households in the same districts (Tables-5 \& 6). These districts include: Gujranwala, Narowal, Sialkot, Sargodha, Lahore, Bahawalpur, Multan, D.G. Khan, Muzzaffargarh, and Bhakkar. This is evident if you calculate the difference in the incidence of rural and overall poverty for each of these districts. The gap between rural poverty and 
overall poverty is much higher indicating that rural households in these districts fare far worse in poverty incidence in comparison to their urban counterparts. As opposed to this we find that rural poverty is only marginally higher than overall poverty in the other districts. The gap between rural and overall poverty is highest in Lahore followed by Bahawalpur and Multan. The difference between rural and overall poverty incidence in Lahore is $25 \%$ and the severity of rural poverty is twice the severity of overall poverty. This suggests that the peri-urban areas of Lahore house a substantial proportion of poor households, which indicates that urbanization is co-exiting with significant poverty.

\subsection{Development Deficits}

To what extent is there an association between poverty in a region and the existence of development deficits in the region? Section 3.3 describes the construction of different deprivation indices that are used to rank the development deficit at the district-level. The results are presented in Table-8. A rank of one means the least deprived or the most developed.

The table shows that all four districts of the north are ranked in the top ten districts in terms of deprivation indices and they maintain their rank in the top ten no matter what index is used. Similarly, nine out of the fourteen districts of south and west Punjab are ranked in the bottom ten districts, which suggests that they are systemically the most deprived. Within central Punjab the high poverty districts of Okara and Pakpattan continue to get ranked in the bottom ten districts. This suggests that there is a negative association between regional poverty and regional development. Even though the direction of causality is unclear, what is clear is that household poverty and district development tend to move together and high poverty enclaves also tend to have high development deficits. 
Table-8: Deprivation Index

\begin{tabular}{|c|c|c|c|c|}
\hline District & Index 1 Rank & Index 2 Rank & Index 3 Rank & Index 4 Rank \\
\hline Rajanpur & 34 & 34 & 31 & 32 \\
\hline Rahimyar Khan & 33 & 32 & 34 & 33 \\
\hline Lodhran & 32 & 33 & 33 & 34 \\
\hline Muzaffargarh & 31 & 31 & 32 & 31 \\
\hline Bahawalpur & 30 & 30 & 29 & 29 \\
\hline D.G. Khan & 29 & 26 & 30 & 25 \\
\hline Okara & 28 & 27 & 28 & 28 \\
\hline Pakpattan & 27 & 28 & 24 & 26 \\
\hline Bhakkar & 26 & 29 & 27 & 30 \\
\hline Bahawalnagar & 25 & 25 & 25 & 27 \\
\hline Layyah & 24 & 24 & 21 & 21 \\
\hline Khanewal & 23 & 23 & 23 & 23 \\
\hline Kasur & 22 & 22 & 20 & 20 \\
\hline Jhang & 21 & 21 & 22 & 22 \\
\hline Vehari & 20 & 20 & 26 & 24 \\
\hline Sahiwal & 19 & 18 & 18 & 18 \\
\hline Multan & 18 & 19 & 17 & 17 \\
\hline Sheikhupura & 17 & 17 & 19 & 19 \\
\hline Hafizabad & 16 & 16 & 15 & 16 \\
\hline Narowal & 15 & 14 & 16 & 15 \\
\hline Khushab & 14 & 15 & 13 & 14 \\
\hline Mianwali & 13 & 13 & 12 & 12 \\
\hline T.T. Singh & 12 & 12 & 14 & 13 \\
\hline Sargodha & 11 & 11 & 10 & 11 \\
\hline Faisalabad & 10 & 10 & 9 & 9 \\
\hline Mandi Bahauddin & 9 & 9 & 11 & 10 \\
\hline Attock & 8 & 8 & 6 & 8 \\
\hline Gujrat & 7 & 7 & 8 & 7 \\
\hline Gujranwala & 6 & 6 & 5 & 5 \\
\hline Jhelum & 5 & 5 & 7 & 6 \\
\hline Sialkot & 4 & 3 & 4 & 4 \\
\hline Lahore & 3 & 2 & 3 & 2 \\
\hline Chakwal & 2 & 4 & 2 & 3 \\
\hline Rawalpindi & 1 & 1 & 1 & 1 \\
\hline
\end{tabular}

Source: MICS (2003-04) (For methodology see section 3.3). 


\section{Conclusion}

This paper provides estimates regarding the incidence and severity of poverty at the regional and the district-level for the Punjab province. Estimates suggest the existence of a high poverty enclave in the south and west regions of the Punjab. The incidence and severity of poverty in a majority of districts in this enclave, with few exceptions, is extremely high with one out of every two households being poor on average. This enclave also does poorly in terms of district-level development indictors.

The high levels of poverty in this enclave contrast with the relatively low poverty in the more urbanized north, where households are well integrated into the national and international labor market. The north does better in spite of low levels of industrialization and dependence on rain-fed agriculture. The experience of the high poverty districts is also in contrast with the more urbanized and industrialized northern districts of the centre. Poverty targeting and development policy must focus its poverty reduction effort on this enclave where poverty appears to be endemic. Taking a Rawlsian perspective we would argue that future growth revival must aim to reduce the poverty gap between the high and low poverty districts and this means that effective redistribution policies and interventions that increase the poor's access to critical assets, such as land and education, and public and collective goods need to be designed. An important area of future research is whether the high growth experience of the 2003-07 period, with its weak redistribution policies, was able to bridge the poverty gap between these regions or did it exacerbate it?

The paper also argues that there is tremendous variation in the poverty experience of the districts in the centre. Poverty incidence in the more urbanized and industrialized northern districts of the centre contrasts sharply with the experience of Kasur, Okara and Pakpattan, where the incidence and severity of poverty is extremely high. Future research must try and explain the reasons for this variation.

Finally, we find that in nine districts rural households do much worse in terms of poverty incidence than their urban counterparts. The gap between urban and rural poverty incidence and severity is highest within the district of Lahore suggesting that urbanization is co-existing with a large poor population that inhabits the peri-urban areas of the district. An important aim of development policy and poverty targeting must be to try and lower the gap between urban and rural poverty in these districts. This also suggests that future research must try and estimate the variation in the intra-district incidence, intensity and severity of poverty and try to identify causal mechanisms that can explain this variation. 


\section{References}

Ali, I., 1988, The Punjab under Imperialism, 1885-1947, Oxford University Press, Karachi.

Cheema, I., 2005, “A Profile of Poverty in Pakistan”, CRPRID Working Paper.

Darling, M., 1947, The Punjab Peasant in Prosperity and Debt, Manohar, New Delhi.

Deaton, \& Zaidi, S., 2002, Guidelines for Constructing Consumption Aggregates for Welfare Analysis, World Bank Publications.

Gazdar, H., 1999, "Poverty in Pakistan: Review", in Fifty Years of Economic Development in Pakistan, Shahrukh Rafi Khan (ed), Oxford University Press, Karachi.

Malik, S.J., 2005, Agricultural Growth and Rural Poverty: Review of the Evidence, Asian Development Bank.

Wilder, A., 1999, The Pakistani Voter, Electoral Politics and Voting Behaviour in the Punjab, Oxford University Press, Karachi.

World Bank, 2002, "Pakistan Poverty Assessment, Poverty in Pakistan: Vulnerabilities, Social Gaps, and Rural Dynamics," Report No. 24296-PAK, South Asia Region. Washington DC. 